\title{
A cerebrospinal fluid leucocidin in pyogenic meningitis
}

\author{
B. M. GREENWOOD
}

From the Department of Medicine, Ahmadu Bello University, Zaria, Nigeria

SUMmARY Cerebrospinal fluid (CSF) samples were tested for their cytotoxicity to polymorphonuclear neutrophil leucocytes (PMN) using a ${ }^{51} \mathrm{Cr}$ release assay. Most samples from patients with? pyogenic meningitis damaged PMN while normal CSF samples did not. No difference was found $\stackrel{\omega}{-}$ between the cytotoxic activity of CSF from patients with pneumococcal meningitis and from patients. with meningococcal meningitis. It is, therefore, unlikely that a CSF leucocidin plays an important $t_{\infty}^{\infty}$ part in producing the high mortality of pneumococcal meningitis.

Ingestion and destruction of bacteria by polymorphonuclear neutrophil leucocytes (PMN) in the meninges and subarachnoid space probably play an important part in recovery from pyogenic meningitis. The cerebrospinal fluid (CSF) of fatal cases of pneumococcal meningitis often contains only a few leucocytes, and we have previously suggested (Tugwell et al., 1976) that defective function of CSF PMN might be one of the factors contributing to the poor prognosis of this infection. In a previous study (Greenwood, 1978) I have shown that the CSF of most patients with pneumococcal meningitis is chemotactic for PMN, even in patients with low CSF white cell counts. I therefore considered the possibility that in these patients PMN were being destroyed as soon as they entered the CSF, and I have looked for a leucocidin in the CSF of patients with pyogenic meningitis.

\section{Patients}

Sixty adult patients with pyogenic meningitis admitted to Ahmadu Bello University Teaching Hospital, Zaria, Nigeria during the period November 1974-April 1975 were studied. Twenty patients had pneumococcal meningitis, 17 group A meningococcol meningitis, and 23 group $C$ meingococcal meningitis. Diagnosis was established by detection of polysaccharide antigen in CSF or on culture.

Control CSF samples were obtained from patients whose clinical features suggested a diagnosis of meningitis but whose CSF proved to be normal.

Received for publication 2 December 1977

\section{Methods}

ROUTINE CSF EXAMINATION

Standard methods were used for CSF white cello count, bacterial count, and protein estimations. Cerebrospinal fluid and blood samples for lactate determination were collected into $0.6 \mathrm{~N}$ perchloric acid. Lactate was measured in the protein-free $\mathbb{Q}$ supernatant by an enzymic method (Boehring Mannheim).

\section{PMN CYTOTOXICITY}

A ${ }^{51} \mathrm{Cr}$ release assay was used to measure damage to PMN. For each assay $50 \mathrm{ml}$ of blood was collected $\overline{0}$ from the same healthy adult donor and layered directly onto Ficoll-Hypaque (Lymphoprep, Nyegaard). After centrifugation at $400 \mathrm{~g}$ for $30 \circ$ minutes at $20^{\circ} \mathrm{C}$ three layers were obtained. The upper plasma layer was removed, centrifuged at 윽 $800 \mathrm{~g}$ for 10 minutes to remove platelets, and retained. The middle band of lymphocytes was removed and discarded. The deposit of red blood $N$ cells and PMN was washed three times in Hanks' medium supplemented with $10 \%$ fetal calf serum $N$ and heparin at a final concentration of 1 unit $/ \mathrm{ml}$. $\omega$ The washed red and white blood cells were remixed with the separated plasma and added to an equalco volume of $3 \%$ dextran in phosphate buffered saline $\frac{\bar{\Phi}}{\Phi}$ at $\mathrm{pH} 7 \cdot 2$. After incubation for one hour the $\stackrel{\mathcal{S}}{+}$ leucocyte-rich supernatant was removed and centri- $T$ fuged. The cell button was then washed three times $\stackrel{\vec{P}}{\Phi}$ in supplemented Hanks' medium. Two millilitres of $\stackrel{\complement}{\overparen{D}}$ distilled water was added to the cell button to lyse $\mathbb{D}$ any residual red cells and after 30 seconds at room temperature isotonicity was restored by the addition 
of $2 \mathrm{ml}$ of twice normal saline. The cell button was then made up in a small volume of Hanks' medium without supplements and the PMN present were counted. Yields were in the range $30-50 \%$. Over $95 \%$ of the white cells present were PMN and only occasional red blood cells were present. Clumping of leucocytes was a problem in some initial experiments. The likelihood of clumping was reduced by carrying out all procedures at room temperature and by washing in Hanks' medium supplemented with fetal calf serum and heparin.

The purified PMN were made up in $0.8 \mathrm{ml}$ of Hanks' medium without supplements and added to $0.2 \mathrm{ml}$ of Hanks' medium containing $200 \mu \mathrm{C}$ of ${ }^{51} \mathrm{Cr}$ sodium chromate. After incubation at $25^{\circ} \mathrm{C}$ for 30 minutes free ${ }^{51} \mathrm{Cr}$ was removed by repeated washing with supplemented Hanks' medium. The washed leucocytes were finally suspended in Hanks' medium at a concentration of $1 \times 10^{10} / 1$.

CSF samples for cytotoxic assay were collected into heparin or ethylenediaminetetra-acetic acid (EDTA) and centrifuged, and the supernatants were kept at $-20^{\circ} \mathrm{C}$ until tested. To assay its cytotoxicity $0.4 \mathrm{ml}$ of CSF supernatant was added to $0.1 \mathrm{ml}$ of the suspension of labelled leucocytes in a tissue culture tube. After incubation at $37^{\circ} \mathrm{C}$ with occasional shaking $2 \mathrm{ml}$ of Hanks' medium was added, the tube was centrifuged, and the supernatant removed. The radioactivity of the supernatant and deposit was counted in a $\gamma$-scintillation counter and a cytotoxicity index calculated $=\%$ release of ${ }^{51} \mathrm{Cr}$ in the test sample - $\%$ release of ${ }^{51} \mathrm{Cr}$ in a tissue culture medium control.

Initial assays showed that ${ }^{51} \mathrm{Cr}$ release on incubation of leucocytes with CSF reached a maximum at about two hours (Fig. 1). This incubation time was therefore used in all subsequent experiments.

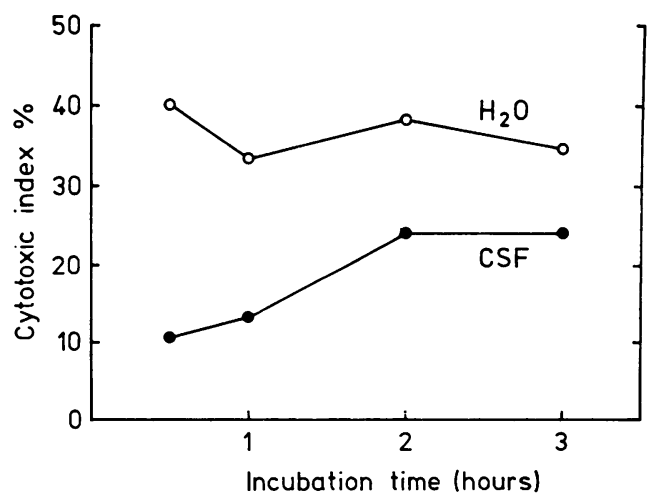

Fig. 1 Influence of time on release of ${ }^{51} \mathrm{Cr}$ from labelled PMN incubated in CSF or distilled water.
After a two-hour incubation ${ }^{51} \mathrm{Cr}$ release in tissue culture medium was approximately $10 \%$ of the maximal possible release. Incubation with distilled water gave approximately $60 \%$ of the maximal possible release. Six CSF samples were tested on three occasions to test the reproducibility of the assay. The mean error between investigations was $\pm 17 \%$. Four samples which had been collected into both heparin and EDTA were tested in the same assay; comparable results were obtained. Incubation of leucocytes with increasing dilutions of a cytotoxic CSF sample showed a linear decrease in ${ }^{51} \mathrm{Cr}$ release.

\section{Results}

\section{ROUTINE CSF FINDINGS}

The results of routine CSF investigations in the three groups of patients studied are shown in Table 1. The mean bacterial count was significantly higher in the CSF of patients with pneumococcal meningitis than in that of patients with meningococcal meningitis but other findings were similar. All patients had raised levels of CSF lactate while blood levels were usually normal or only slightly raised.

Table 1 CSF cell and bacterial counts, protein, and lactate levels in 60 patients with pyogenic meningitis (mean $\pm 1 S D)$

\begin{tabular}{|c|c|c|c|c|}
\hline $\begin{array}{l}\text { Type of } \\
\text { meningitis }\end{array}$ & $\begin{array}{l}\text { Cell } \\
\text { count } \\
\left(\times 10^{9} / l\right)\end{array}$ & $\begin{array}{l}\text { Bacterial } \\
\text { count } \\
\left(\times 10^{\circ} / l\right)\end{array}$ & $\begin{array}{l}\text { Protein } \\
(g / l)\end{array}$ & $\begin{array}{l}\text { Lactate } \\
\text { (mmol/l) }\end{array}$ \\
\hline $\begin{array}{l}\text { Pneumococcal } \\
(n=20)\end{array}$ & $7 \cdot 3 \pm 18 \cdot 0$ & $146 \pm 186$ & $6 \cdot 5 \pm 4 \cdot 2$ & $11 \cdot 3 \pm 5 \cdot 3$ \\
\hline $\begin{array}{c}\text { Meningococcal } \\
\text { A }(n=17)\end{array}$ & $11 \cdot 3 \pm 10 \cdot 3$ & $15 \pm 17$ & $6.9 \pm 4.0$ & $11 \cdot 7 \pm 7 \cdot 2$ \\
\hline $\begin{array}{c}\text { Meningococcal } \\
\mathrm{C}(\mathbf{n}=23)\end{array}$ & $8.8 \pm 6.6$ & $25 \pm 26$ & $4 \cdot 2 \pm 2 \cdot 4$ & $10 \cdot 1$ 上 6.3 \\
\hline
\end{tabular}

CYTOTOXICITY OF CSF TO PMN

Incubation of labelled PMN in 10 samples of normal CSF showed only a small increase in the release of ${ }^{51} \mathrm{Cr}$ over that observed in tissue culture medium controls $(8 \% \pm 4)$. Cerebrospinal fiuid from nearly all patients with meningitis caused a more pronounced release of ${ }^{51} \mathrm{Cr}$, in some cases to the level produced by distilled water (Fig. 2). No difference was found between the mean cytotoxic activity of CSF from patients with pneumococcal meningitis and from those with meningococcal meningitis. The results obtained with CSF from patients with group A meningococcal meningitis or group $\mathrm{C}$ meningococcal meningitis were very similar, and data from these two groups of patients have therefore been pooled. 


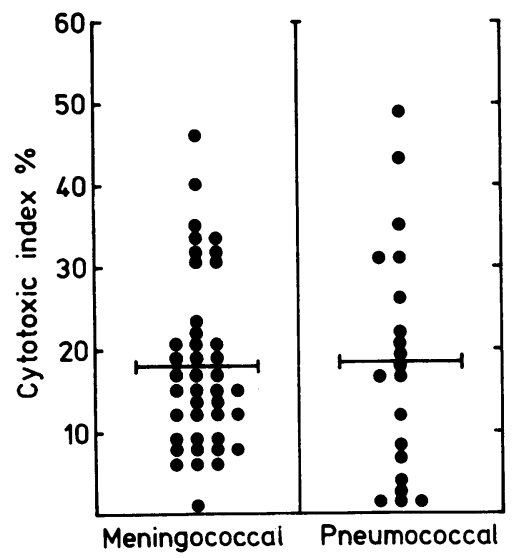

Fig. 2 Cytotoxicity of CSF from patients with pneumococcal or meningococcal meningitis to ${ }^{51} \mathrm{Cr}$ labelled PMN.

CORRELATION OF CSF CYTOTOXICITY WITH CLINICAL AND OTHER LABORATORY

FINDINGS

Nine of the 20 patients with pneumococcal meningitis died. The mean cytotoxic index of their CSF (36\% 18) did not differ significantly from the mean cytotoxic index of the 11 survivors $(37 \% \pm 13)$. No significant correlation was found between the cytotoxic activity of individual CSF samples and the CSF cell count, bacterial count, protein or lactate level.

NATURE OF CSF CYTOTOXIC FACTOR

The effects of heating and dialysis on the cytotoxic activity of pooled samples of CSF from patients with pneumococcal or meningococcal meningitis are shown in Table 2 . Release of ${ }^{51} \mathrm{Cr}$ from labelled leucocytes was unaffected by heating to $56^{\circ} \mathrm{C}$ for 20 minutes but was partially reduced by heating to $100^{\circ} \mathrm{C}$ for 5 minutes. The activity of each pool

Table 2 Effects of heating and dialysis on cytotoxicity of three CSF pools to peripheral blood PMN. (Results are expressed as a cytotoxic index derived as indicated in the text. The mean results of three experiments are recorded)

\begin{tabular}{llll}
\hline & \multicolumn{1}{l}{ Pool } & \\
\cline { 2 - 4 } & $\begin{array}{l}\text { Meningococcal } \\
A\end{array}$ & $\begin{array}{l}\text { Meningococcal } \\
C\end{array}$ & Pneumococcal \\
\hline $\begin{array}{l}\text { Untreated } \\
\text { Heated to } 56^{\circ} \mathrm{C}\end{array}$ & 30 & 30 & 23 \\
$\begin{array}{c}\text { for } 20 \text { min } \\
\text { Heated to } 100^{\circ} \mathrm{C} \\
\text { for 5 min }\end{array}$ & 15 & 43 & 31 \\
$\begin{array}{c}\text { Dialysed } \\
\text { folysed }\end{array}$ & -4 & 28 & 18 \\
\hline
\end{tabular}

was completely removed by dialysis across a $\stackrel{0}{\overrightarrow{5}}$ membrane with a pore size of approximately $10000 \%$ daltons.

\section{Discussion}

In 1934 Oram reported that filtrates of pneumococcal cultures impaired the ability of leucocytes to reduce $\cong$

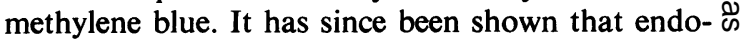
toxin and other bacterial products can interfere with $\vec{\circ}$ the bactericidal functions of PMN in vitro (Koch, 1975). It is, therefore, not surprising that the PMN $\vec{\omega}$ of patients with a variety of acute bacterial infections are unable to kill bacteria normally (Solberg? and Hellum, 1972). In a preliminary study I found $\stackrel{\omega}{-}$ that the ability of PMN obtained from the CSF of two patients with pneumococcal meningitis to kill $\underset{\infty}{\circ}$ Staphylococcus aureus was severely impaired. Direct ${ }^{\infty}$ study of the functions of CSF PMN from untreated 5 cases of pyogenic meningitis is difficult, and $\mathrm{I}_{\vec{C}}^{\vec{C}}$ therefore set up an in vitro assay in which the cytotoxicity of CSF to PMN could be tested directly. -

CSF from most patients with pyogenic meningitis 9 proved to be toxic to PMN as judged by the release ${ }^{\infty}$ of ${ }^{51} \mathrm{Cr}$ from labelled cells. In a separate series of experiments, not reported here, I have also found that the incubation of leucocytes in CSF fromo patients with pyogenic meningitis impairs their ability to kill Candida albicans and to migrate $\stackrel{\mathbb{Q}}{\mathscr{Q}}$ towards a chemotactic stimulus. As in the present $\overrightarrow{\vec{F}}$ study, no significant difference was observed $\stackrel{3}{3}$ between the effects of CSF obtained from patients? with pneumococcal meningitis and from those witho meningococcal meningitis. These findings are in agreement with those of a recent report by Bratlid? and Bøvre (1977), who found that CSF from patients with pyogenic meningitis caused lysis of a micrococcus while normal CSF or CSF from patients with viral meningitis did not. It was suggested that the toxic factor was lysozyme.

The leucocidin demonstrated in CSF from patients with pyogenic meningitis proved to be a․ low molecular weight compound partially degraded N by heating to $100^{\circ} \mathrm{C}$. It is thus unlikely to be the capsular polysaccharide. It is also unlikely to be lactic acid as no correlation was found between the ${ }^{\omega}$ cytotoxicity and the lactate level of individual CSF? samples. It may be similar to the pneumococcale leucocidin described by Oram (1934), which was partially heat labile and readily oxidised. More than ${ }^{-}$ one cytotoxic factor may be involved.

This study was undertaken to investigate the hypothesis that production of a leucocidin by pneumococci in the CSF might be an importanto factor underlying the poor prognosis of manye patients with pneumococcal meningitis. Althougho 
a leucocidin was found, my results do not support this hypothesis as the CSF of patients with meningococcal meningitis, a condition with a much better prognosis, proved to be as cytotoxic as CSF obtained from patients with pneumococcal meningitis. Furthermore, in patients with pneumococcal meningitis no correlation was found between CSF cytotoxic activity and the outcome of the infection or between CSF cytotoxicity and other CSF findings. The mechanisms underlying the poor outlook of patients with pneumococcal meningitis remain to be explained.

I thank my colleagues who helped with the collection of CSF samples. The study was supported by the United Kingdom Medical Research Council.

\section{References}

Bratlid, D., and Bøvre, K. (1977). Bacteriolytic activity of normal and pathological cerebrospinal fluid Acta Pathologica Microbiologica Scandinavica, 85C 21-25.

Greenwood, B. M. (1978). Chemotactic activity of cerebrospinal fluid in pyogenic meningitis. Journal of Clinical Pathology, 31, 213-216.

Koch, C. (1975). Influence of endotoxin and complex bacterial antigens in the presence of serum factors upon the function of human neutrophils in vitro. Acta Pathologica Microbiologica Scandinavica, 83C, 195-202.

Oram, F. (1934). Pneumococcus leucocidin. Journal of Immunology, 26, 233-246.

Solberg, C. O., and Hellum, K. B. (1972). Neutrophil granulocyte function in bacterial infections. Lancet, 2, 727-730.

Tugwell, P., Greenwood, B. M., and Warrell, D. A. (1976). Pneumococcal meningitis: a clinical and laboratory study. Quarterly Journal of Medicine, 45, 583-601.

Requests for reprints to: Dr B. M. Greenwood, Department of Medicine, Ahmadu Bello University Hospital, Zaria, Nigeria. 